\title{
Effect of Thermal Processing on Simultaneous Formation of Acrylamide and Hydroxymethylfurfural in Plum Purée
}

\author{
Oana Emilia Constantin ${ }^{1}$, Kristina Kukurová2, Lubomír Daško², Nicoleta Stănciuc ${ }^{1}$, \\ Zuzana Ciesarová2, Constantin Croitoru ${ }^{3}$, Gabriela Râpeanu ${ }^{1 *}$
}

\author{
${ }^{\prime}$ Integrated Center for Research, Expertise and Technological Transfer in Food Industry, \\ Faculty of Food Science and Engineering, Dunărea de Jos University of Galati, 111 Domnească Street, 800201, Galati, Romania \\ ${ }^{2}$ VUP Food Research Institute, National Agricultural and Food Centre, \\ Department of Chemistry and Food Analysis, Priemyslená 4, 82475 Bratislava, Slovakia \\ ${ }^{3}$ Academy of Agricultural and Forestry Sciences, 61 Marasti Blvd, 011464 Bucharest, Romania
}

Key words: acrylamide, hydroxymethylfurfural, plums purée, temperature, time, thermal treatment

The formation of acrylamide (ACR) and hydroxymethylfurfural (HMF) at different time and temperature combination in plum purée derived from two species was investigated. An optimized method for reducing ACR and HMF formation in thermally-treated plum purée was developed using a Central Composite Design model. Precursors of contaminants and their influence on the heating of plum purée were evaluated as well. The contaminants content was determined in thirteen running variants in the temperature range of $59.3-200.7^{\circ} \mathrm{C}$, and heating time between 5.9 and $34.1 \mathrm{~min}$. The model allowed establishing that the lowest ACR content was reached at 5.9-min exposure time and $130^{\circ} \mathrm{C}$ temperature, for both plum species $(3.91 \mu \mathrm{g} / \mathrm{kg}$ and $8.73 \mu \mathrm{g} / \mathrm{kg}$ for Prunus cerasifera (P1) and Prunus domestica (P2), respectively). The lowest quantity of HMF was found at 20-min exposure time and $59.3^{\circ} \mathrm{C}$ temperature for both plum species $(0.25 \mathrm{mg} / \mathrm{kg}$ and $0.18 \mathrm{mg} / \mathrm{kg}$ for P1 and P2, respectively). The results obtained allowed predicting the ACR/HMF levels in plum purée at different heating conditions.

\section{INTRODUCTION}

Plums are fruits rich in vitamins, minerals, antioxidants, and other bioactive components, with numerous health benefits [Birwal et al., 2017]. Consumption of fresh thermally-treated plums (prunes, juice, compote, and jam) may prevent from anemia, constipation, obesity, and cardiovascular diseases [Sahamishirazi et al., 2017]. During thermal treatment of plums, beside the desired sensorial properties, different compounds can be found such as advanced glycation end products (AGEs) and low-molecular-mass browning products such as acrylamide (ACR) and 5-hydroxymethylfurfural (HMF) [Nguyen et al., 2016]. Their possible mutagenic, carcinogenic, and/or cytotoxic effects have been proved in previous research [Nursten, 2005]. In 2002, the Swedish National Food Administration added ACR to the list of food-borne toxic compounds, which have been found in high amounts in some heat-treated, carbohydrate-rich foods such as potato chips and crisps, coffee and bread [Swedish National Food Administration, 2002], and later in hazelnuts and almonds [Amrein et al., 2007], dried fruits [Kukurová et al., 2015], and vegetables [Constantin et al., 2014]. Different pathways

\footnotetext{
* Corresponding Author: Tel.: 004-0336 130 177; Fax: 004-0236 460 165;

E-mail: Gabriela.Rapeanu@ugal.ro (Prof. G. Rapeanu)
}

for ACR formation in foods have been reported such as Maillard reaction between free asparagine as the primary precursor and sugars [Zyzak et al., 2003; Blank et al., 2005]; formation from acrolein and acrylic acid [Yasuhara et al., 2003]; formation from wheat gluten [Claus et al., 2006], and from 3-aminopropionamide (3-APA) [Granvogl \& Schieberle, 2006].

$\mathrm{HMF}$ is an organic compound included into the class of furans. It is formed as an intermediate in the Maillard reaction or through fructose dehydration under acidic conditions at elevated temperatures. HMF was found in bakery products, honey, malt, fruit products, coffee, vinegar, and dried fruit [Capuano \& Fogliano, 2011]. In literature, a high variability in ACR and HMF contents has been reported between different studied products, which was mainly influenced by the difference in food composition including precursors' content (free asparagine and reducing sugars) present in raw materials and in process conditions applied $(\mathrm{pH}$, water activity, temperature/time combination, presence of divalent cations) [Gökmen et al., 2008]. These two neo-formed contaminants (NFC) are very interesting because of their high occurrence in food and toxicological potential such as mutagenic, carcinogenic and cytotoxic effects [Capuano \& Fogliano, 2011]. The purpose of this study was to find out information on acrylamide and 5-hydroxymethylfurfural formation during 
thermal treatment of plum purée at different combinations of time and temperature. This study will help food processors to establish the optimal temperature/time combination to obtain lower amounts of ACR and HMF in the final product.

\section{MATERIALS AND METHODS}

\section{Reagents and chemicals}

Internal standards: 2,2,3- $d 3$-2-propenamide ( $d 3$-ACR) and 2,4,4- $d 3$-glutamic acid ( $d 3$-Glu), purity $97-98 \%$ were achieved from Cambridge Isotope Laboratories (Andover, Maryland, USA); standard of acrylamide (ACR), purity $99 \%$, 21 L-Amino Acids Kit: L-alanine $\geq 98 \%$ (Ala), L-arginine monohydrochloride $\geq 98 \%$ (Arg), L-asparagine $\geq 98 \%$ (Asn), L-aspartic acid $\geq 98 \%$ (Asp), L-cysteine hydrochloride anhydrous $\geq 98 \%$ (Cys), L-glutamine $\geq 99 \%$ (Gln), L-glutamic acid $\geq 99 \%$ (Glu), L-glycine $\geq 99 \%$ (Gly), L-histidine monohydrochloride monohydrate $\geq 98 \%$ (His), trans-4-hydroxy-L-proline $\geq 98 \%$ (Hyp), L-isoleucine $\geq 98 \%$ (Ile), L-leucine $\geq 98 \%$ (Leu), L-lysine monohydrochloride $\geq 98 \%$ (Lys), L-methionine $\geq 98 \%$ (Met), L-phenylalanine $\geq 98 \%$ (Phe), L-proline $\geq 99 \%$ (Pro), L-serine $\geq 99 \%$ (Ser), L-threonine $\geq 98 \%$ (Thr), L-tryptophan $\geq 98 \%$ (Trp), L-tyrosine $\geq 98 \%$ (Tyr), L-valine $\geq 98 \%$ (Val), and L-ornithine $\geq 98 \%$ (Orn), hydroxymethylfurfural (HMF) 99\% purity, perfluorooctanoic acid (PFOA) 96\%, and acetonitrile HPLC gradient grade were purchased from Sigma-Aldrich (Steinheim, Germany); ethyl acetate and acetic acid glacial grade were purchased from Fischer Scientific (Loughborough, UK); methanol HPLC-grade, potassium hexacyanoferrate trihydrate, and zinc sulfate heptahydrate were achieved from Merck (Schuchardt, Germany). Nylon syringe filters $(0.45 \mu \mathrm{m})$ were obtained from Waters (Milford, Milford, MA, USA).

\section{Plant material}

Fruits of two plum species: Prunus cerasifera - cherry plum (P1) and Prunus domestica Angeleno (P2), were used in this study. The selected plums represented the offseason species available on the Romanian market. Plums have been purchased on the local market and stored at $4^{\circ} \mathrm{C}$ before analysis. The dry matter content was determined with a classic thermogravimetric method (removing the water using an oven at $105^{\circ} \mathrm{C}$ temperature) and revealed the following values in plums: $10.18 \%$ for $\mathrm{P} 1$ and $9.03 \%$ for P2. Plums were washed, homogenized at 10,000 rpm for $15 \mathrm{~s}$ (Grindomix Retsch GM200), and heat treated according to the experimental model.

\section{Extraction and analysis of plum purée amino acids}

For the determination of amino acids, $2 \mathrm{~g}$ of plum purée were weighed into a $10-\mathrm{mL}$ centrifuge tube. The extraction solution $(20 \mathrm{~mL}, 0.1 \%$ acetic acid $(\mathrm{v} / \mathrm{v}))$ was added to the sample and stirred for 30 min at $150 \mathrm{rpm}$ (Heidolph Unimax 2010, Schwabach, Germany) and centrifuged at $19,621 \times g$ for $10 \mathrm{~min}$ (Sigma 2-16 KC, Germany). The samples were diluted using the following protocol: $100 \mu \mathrm{L}$ of the clear supernatant of each sample were transferred to a $10-\mathrm{mL}$ volumetric flask, $50 \mu \mathrm{L}$ of $d 3$-Glu (stock solution 10-fold diluted) were added, and the flask was filled up with $0.1 \%$ acetic acid (v/v). The extract was filtered through a $0.45 \mu$ m nylon syringe filter before the LC/MS analysis. The LC/ESI-MS-MS analyses for quantification of free amino acids profile were performed in the HPLC system 1200 series coupled to an Agilent 6410 Triple Quad detector equipped with ESI interface (Agilent Technologies, Santa Clara, California, USA). The analytical separation was performed on a Purospher STAR RP-8ec column ( $4.6 \times 150 \mathrm{~mm}, 3 \mu \mathrm{m}$ particle size) (Merck, Darmstadt, Germany) using an isocratic elution with a mixture of $100 \mathrm{~mL}$ of acetonitrile and $900 \mathrm{~mL}$ of aqueous solution of PFOA $(0.05 \mathrm{Mm})$ at a flow rate $0.5 \mathrm{~mL} / \mathrm{min}$ at ambient temperature. All parameters of the electrospray ionization tandem mass spectrometry (ESI-MS-MS) system were based on in-source generation of the protonated molecular ions of the amino acids measured and the internal standard $(d 3$-Glu) as well as collision-induced production of amino acid-specific fragment ions for Multiple Reaction Monitoring (MRM) experiments [Constantin et al., 2014].

\section{Reducing sugars content determination}

Determination of the content of reducing sugars was performed using the 3,5-dinitrosalicylic acid (DNS) according to AOAC method [1995]. Briefly, $2 \mathrm{~mL}$ of the sample homogenized with $2 \mathrm{~mL}$ of $0.04 \mathrm{M}$ DNS solution were maintained in a boiling-water bath for $10 \mathrm{~min}$. After cooling, the contents of the tubes were brought to the volume of $10 \mathrm{~mL}$ with distilled water. The absorbance of the mixture was measured at $535 \mathrm{~nm}$ wavelength against a prepared blank using a Jenway 6506 UV-Vis Spectrophotometer (Cole-Parmer, Stone, United Kingdom). The results were expressed as mg glucose/g DW.

\section{Thermal treatment and experimental design}

Plum puree was subjected to heat treatment using a thermostat (Liebisch Labortechnik, Germany), in a range of temperatures between 59.3 and $200.7^{\circ} \mathrm{C}$, and heating times between 5.9 and $34.1 \mathrm{~min}$ according to the experimental model parameters of which are presented in Table 1. Central Composite Design (CCD) and response surface modeling have been used to optimize the thermal treatment of plum purée to obtain ACR and HMF. CCD builds a quadratic model for response variables. The design involves three distinct sets of steps: a factorial design on the variables studied, a set of focal points and a set of points or samples axial stay. The design investigates five levels of each variable studied. Circumscribed data set was used, with a distance of \pm 1.4142 proven stars. The experiments were carried out in the order given by the software to determine the influence of external factors in the analysis. Two parameters were analyzed such as temperature and time of thermal treatment, and contents of ACR and HMF were selected as the answers Design-Expert ${ }^{\circledR}$ software (Stat-Ease, Inc.) was used for data analysis.

The experimental conditions can be described by equation (1).

$$
\mathrm{R}=\mathrm{b}_{0}+\mathrm{b}_{1} \mathrm{~A}+\mathrm{b}_{2} \mathrm{~B}+\mathrm{b}_{3} \mathrm{AB}+\mathrm{b}_{4} \mathrm{~A}^{2}+\mathrm{b}_{5} \mathrm{~B}^{2}
$$

where: A, B are independent variables studied and $b_{0}-$ intercept, $b_{1}-b_{5}$ represent regression coefficients, constants for 
TABLE 1. Matrix of experimental design (coded levels and real values) with responses in terms of acrylamide (ACR) and hydroxymethylfurfural (HMF) content in purée made of Prunus cerasifera (P1) and Prunus domestica (P2) plums.

\begin{tabular}{|c|c|c|c|c|c|c|c|c|}
\hline \multirow[b]{2}{*}{ Run } & \multicolumn{2}{|c|}{ Coded levels } & \multicolumn{2}{|c|}{ Actual levels } & \multicolumn{2}{|c|}{ Plum purée P1 } & \multicolumn{2}{|c|}{ Plum purée P2 } \\
\hline & $\begin{array}{c}\text { Temperature } \\
\left({ }^{\circ} \mathrm{C}\right) \\
(\mathrm{A})\end{array}$ & $\begin{array}{c}\text { Time } \\
(\mathrm{min}) \\
(\mathrm{B})\end{array}$ & $\begin{array}{c}\text { Temperature } \\
\left({ }^{\circ} \mathrm{C}\right) \\
(\mathrm{A})\end{array}$ & $\begin{array}{c}\text { Time } \\
(\min ) \\
(\mathrm{B})\end{array}$ & $\begin{array}{c}\mathrm{ACR} \\
(\mu \mathrm{g} / \mathrm{kg} \mathrm{DW})\end{array}$ & $\begin{array}{c}\mathrm{HMF} \\
(\mathrm{mg} / \mathrm{kg} \mathrm{DW})\end{array}$ & $\begin{array}{c}\mathrm{ACR} \\
(\mu \mathrm{g} / \mathrm{kg} \mathrm{DW})\end{array}$ & $\begin{array}{c}\mathrm{HMF} \\
(\mathrm{mg} / \mathrm{kg} \mathrm{DW})\end{array}$ \\
\hline 1 & 0 & 0 & 130 & 20 & 21.50 & 34.73 & 9.92 & 4.68 \\
\hline 2 & -1 & +1 & 80 & 30 & 35.28 & 25.38 & 50.55 & 2.85 \\
\hline 3 & -1.41 & 0 & 59.3 & 20 & 8.49 & 0.25 & 31.72 & 0.18 \\
\hline 4 & -1 & -1 & 80 & 10 & 5.48 & 0.34 & 15.99 & 0.51 \\
\hline 5 & 0 & 0 & 130 & 20 & 30.18 & 34.69 & 12.30 & 4.53 \\
\hline 6 & 0 & 0 & 130 & 20 & 27.37 & 34.53 & 9.85 & 5.48 \\
\hline 7 & 0 & 0 & 130 & 20 & 22.74 & 32.75 & 11.57 & 3.94 \\
\hline 8 & 0 & -1.41 & 130 & 5.9 & 3.91 & 35.17 & 8.73 & 0.45 \\
\hline 9 & +1.41 & 0 & 200.7 & 20 & 1024.89 & 139.06 & 634.75 & 90.40 \\
\hline 10 & 0 & 0 & 130 & 20 & 22.70 & 31.86 & 15.07 & 3.79 \\
\hline 11 & +1 & 0 & 180 & 30 & 876.68 & 100.72 & 596.89 & 92.88 \\
\hline 12 & 0 & +1.41 & 130 & 34.1 & 552.29 & 95.36 & 79.42 & 25.19 \\
\hline 13 & +1 & -1 & 180 & 10 & 447.77 & 116.89 & 263.18 & 57.03 \\
\hline
\end{tabular}

the effect of the general process, the linear and quadratic effects of each independent variable, as well as the interaction effects of the variables on the content of ACR and HMF.

\section{ACR content determination}

After heat processing of plum purée, ACR was extracted with $30 \mathrm{~mL}$ of $0.1 \%$ acetic acid (v/v) and further pre-extracted with ethyl acetate to avoid the negative impact of salts in the chromatographic system according to procedures published before by Constantin et al. [2014] and Ciesarová et al. [2009]. Acetic acid extraction step was repeated three times. The samples were shaken for $1 \mathrm{~min}$ and then clarified with $1 \mathrm{~mL}$ of Carrez solution I (15\% potassium ferrocyanide) and $1 \mathrm{~mL}$ of Carrez solution II (30\% zinc acetate). The acetic acid extracts were collected and brought to a total volume of $100 \mathrm{~mL}$ with $0.1 \%$ acetic acid (v/v). After mixing for $1 \mathrm{~min}$ and sonication for $10 \mathrm{~min}$, the samples were shaken by a vortex mixer for $1 \mathrm{~min}$, sonicated for $5 \mathrm{~min}$, and centrifuged at $-5^{\circ} \mathrm{C}$ for $10 \mathrm{~min}$ at $19,621 \times g$ (Sigma 2-16 KC, Germany). A volume of $5 \mathrm{~mL}$ of the clear supernatant was transferred to a test tube with the addition of $100 \mu \mathrm{L}$ of internal standard $d 3$-ACR solution (2 $\mathrm{mg}$ in $100 \mathrm{~mL}$ of water) and $5 \mathrm{~mL}$ of ethyl acetate, and mixed well for 1 min. The ethyl acetate top layer was removed to a clean test tube. The step of preextraction with ethyl acetate was repeated three times, and all the ethyl acetate layers were collected and evaporated under vacuum at $35^{\circ} \mathrm{C}$ to dryness. The dry residue was dissolved in $1 \mathrm{~mL}$ of $0.1 \%$ acetic acid (v/v) and filtered through a nylon syringe filter with $0.45 \mu \mathrm{m}$ pore size to glass vials before LC-MS analysis.

The LC/ESI-MS-MS technique using the 1260 Infinity HPLC system coupled to 6410 Triple Quad LC/MS equipped with ESI interface (Agilent Technologies, Santa Clara, California, USA) was applied. The analytical separation was performed on Atlantis dC18 column $(30 \times 100 \mathrm{~mm}, 3 \mu \mathrm{m}$ pore size, Waters, Milford, MA, USA) using isocratic elution of $1 \%$ methanol ( $\mathrm{v} / \mathrm{v})$ and $0.2 \%$ acetic acid $(\mathrm{v} / \mathrm{v})$ in water as a mobile phase at $0.4 \mathrm{~mL} / \mathrm{min}$ flow rate at $25^{\circ} \mathrm{C}$. All parameters of the electrospray ionization tandem mass spectrometry (ESI-MS-MS) system were based on in-source generation of the protonated molecular ions of ACR and the internal standard (d3-ACR), as well as collision-induced production of specific fragment ions for MRM experiments (transition for ACR: $72 \rightarrow 55$, transition for $d 3$-ACR: $75 \rightarrow 58$ ). The following instrumental parameters were used for ACR analysis in the ESI+ mode: drying gas $\left(\mathrm{N}_{2}\right)$ flow of $8 \mathrm{~L} / \mathrm{min}$, gas temperature of $350^{\circ} \mathrm{C}$, nebulizer pressure of $345 \mathrm{kPa}$, capillary voltage of $2.5 \mathrm{kV}$, fragmentor of $80 \mathrm{~V}$, collision energy of $5 \mathrm{eV}$, and dwell $50 \mathrm{~ms}$. Calibration was performed by diluting the ACR stock solution $(5 \mathrm{mg}$ in $100 \mathrm{~mL}$ of water) in the range of $10-2000 \mathrm{ng} / 10 \mathrm{~mL}$ with $50 \mu \mathrm{L}$ of the internal standard (d3-ACR).

\section{HMF content determination}

After heat processing of plum purée, HMF was extracted with $30 \mathrm{~mL}$ of a methanol: water mixture $(80: 20, \mathrm{v} / \mathrm{v})$. The mixture was sonicated for $5 \mathrm{~min}$, centrifuged for $10 \mathrm{~min}$ at 19,621 ×g (Sigma 2-16 KC, Germany) and filtered through $0.45 \mu \mathrm{m}$ nylon membrane syringe filters. Agilent 1200 HPLC system (Agilent Technologies, Santa Clara, California, USA) equipped with UV/VIS detector (DAD) was used for HMF analysis. The chromatographic separation was performed on C18 SB column $(4.6 \times 250 \mathrm{~mm}$, particle size $5 \mu \mathrm{m}$, Waters, Milford, MA, USA) using the gradient elution at a flow 
TABLE 2. Contents of amino acids and reducing sugar in purée made of Prunus cerasifera (P1) and Prunus domestica (P2) plums.

\begin{tabular}{|c|c|c|c|}
\hline \multirow{2}{*}{ Compound } & & \multicolumn{2}{|c|}{ Plum purée } \\
\hline & & P1 & P2 \\
\hline \multirow{22}{*}{$\begin{array}{l}\text { Amino acids } \\
(\mathrm{mg} / \mathrm{kg} \mathrm{DW})\end{array}$} & Нyp* & $0.28 \pm 0.09$ & $0.00 \pm 0.00$ \\
\hline & Asp* & $5.56 \pm 0.10$ & $4.93 \pm 0.10$ \\
\hline & Pro* & $51.93 \pm 0.75$ & $39.65 \pm 0.45$ \\
\hline & Asn* & $178.41 \pm 1.01$ & $138.78 \pm 0.35$ \\
\hline & Ser & $5.95 \pm 0.02$ & $5.88 \pm 0.19$ \\
\hline & Gln* & $34.08 \pm 0.36$ & $91.51 \pm 0.01$ \\
\hline & Thr* & $3.32 \pm 0.05$ & $3.40 \pm 0.07$ \\
\hline & Glu* & $5.64 \pm 0.10$ & $8.59 \pm 0.23$ \\
\hline & Gly* & $0.73 \pm 0.08$ & $0.72 \pm 0.11$ \\
\hline & $\mathrm{Ala}^{*}$ & $10.22 \pm 0.22$ & $13.15 \pm 0.18$ \\
\hline & Val & $3.06 \pm 0.02$ & $5.05 \pm 0.06$ \\
\hline & Met & $0.00 \pm 0.00$ & $0.00 \pm 0.00$ \\
\hline & Tyr & $0.00 \pm 0.00$ & $0.00 \pm 0.00$ \\
\hline & Ile* & $2.38 \pm 0.02$ & $6.08 \pm 0.03$ \\
\hline & Leu* & $2.40 \pm 0.02$ & $6.07 \pm 0.03$ \\
\hline & Phe* & $1.40 \pm 0.05$ & $3.58 \pm 0.02$ \\
\hline & His* & $2.71 \pm 0.23$ & $1.34 \pm 0.05$ \\
\hline & Orn* & $0.27 \pm 0.03$ & $0.38 \pm 0.01$ \\
\hline & Lys* & $0.54 \pm 0.00$ & $0.97 \pm 0.00$ \\
\hline & Arg* & $0.32 \pm 0.05$ & $0.79 \pm 0.08$ \\
\hline & $\operatorname{Trp}$ & $0.16 \pm 0.00$ & $0.41 \pm 0.00$ \\
\hline & Sum & $14.75 \pm 0.11$ & $15.77 \pm 0.00$ \\
\hline $\begin{array}{l}\text { Reducing sugars } \\
\text { (RS) (mg/g DW) }\end{array}$ & RS* & $11.12 \pm 1.03$ & $9.18 \pm 0.34$ \\
\hline
\end{tabular}

Explanations: Hyp - 4-trans-hydroxyproline, Asp - aspartic acid, Pro proline, Asn - asparagine, Ser -serine, Gln - glutamine, Thr -threonine, Glu - glutamic acid, Gly - glycine, Ala - alanine, Val - valine, Met methionine, Tyr - tyrosine, Ile - isoleucine, Leu - leucine, Phe - phenylalanine, His - histidine, Orn - ornithine, Lys - lysine, Arg - arginine, and Trp - tryptophan.

* indicates significant difference between samples $(\mathrm{p}<0.05)$; DW - dry weight.

rate of $0.8 \mathrm{~mL} / \mathrm{min}$ at $25^{\circ} \mathrm{C}$. The mobile phase consisted of $\%$ of methanol (A), $0.01 \mathrm{M} \mathrm{H}_{3} \mathrm{PO}_{4}(\mathrm{~B})$, and acetonitrile (C). Gradient composition for HMF determination was applied as following: $0-1.5 \mathrm{~min}, 0-2 \% \mathrm{~A}, 100-95 \% \mathrm{~B}, 0-3 \%$ C; $1.5-2.1 \mathrm{~min}, 2 \% \mathrm{~A}, 95 \% \mathrm{~B}, 3 \% \mathrm{C} ; 2.1-3.0 \mathrm{~min}, 2-8 \% \mathrm{~A}$, 95-86\% B, 3-6\% C; 3.0-11.0 min, 8\% A, 86\% B, 6\% C; 11.0 $-11.5 \mathrm{~min}, 8-94 \%$ A, 86-0\% B, 6\% C; 11.5-20.0 min, 94\% A, 0\% B, 6\% C; 20.0-20.1 min, 94-2\% A, 0-95\% B, 6-3\% C; 20.1-30.0 $\mathrm{min}, 2 \% \mathrm{~A}, 95 \% \mathrm{~B}, 3 \% \mathrm{C}$.

The HMF was detected at its absorption maximum of $280 \mathrm{~nm}$ and quantified using external calibration curve in the range from 0.05 to $1.0 \mu \mathrm{g} / \mathrm{mL}$.

\section{Statistical analysis}

Data were analyzed using multivariate data analysis and Design Expert v. 10.1 software from Design-Expert ${ }^{\circledR}$ (Stat-Ease, Inc., Minnesota, USA) and by paired t-test using SPSS19.0 (IBM, New York, NY, USA).

\section{RESULTS AND DISCUSSION}

\section{Contents of amino acids and reducing sugars in plum purée}

The purées from fresh red plum were analyzed for ACR and HMF precursors, and the results of determinations of contents of amino acids and reducing sugars are presented in Table 2. The amino acids analysis showed a high asparagine content in both plums compared to other amino acids $(178.41 \pm 1.01 \mathrm{mg} / \mathrm{kg}$ DW for P1 and $138.78 \pm 0.35 \mathrm{mg} / \mathrm{kg}$ DW for P2). It is known that asparagine is a crucial participant in the production of ACR in the Maillard reaction [Mottram et al., 2002]. Its high content in $\mathrm{P} 1$ and $\mathrm{P} 2$ plum purée may be considered responsible for the ACR formation.

Reducing sugars content in P1 and P2 plums purée was $11.12 \pm 1.03 \mathrm{mg} / \mathrm{g}$ DW and $9.18 \pm 0.34 \mathrm{mg} / \mathrm{g}$ DW, respectively. Leong \& Oey [2012] obtained similar results $(9.70 \pm 0.98$ - 16.54 $\pm 0.04 \mathrm{mg} / \mathrm{g} \mathrm{DW}$ ) for plum from the Otago region (South Island, New Zealand). The presence of reducing sugars is essential in both ACR and HMF formation, as they form a Schiff base with asparagine, and then by decarboxylation ACR, while HMF is formed by their caramelization or thermal dehydration [Friedman, 1996; Abraham et al., 2011].

\section{Thermal treatment optimization}

The Central Composite Design (CCD) and surface response modeling were used to determine the optimal parameters (temperature and time) of the thermal treatment of plum purée, and to achieve minimal contents of ACR and HMF. Table 1 presents the matrix of the complete CCD used in optimization with actual values of the main variables studied, and the corresponding values of the ACR and HMF content measured. The optimized coded model for contaminants was represented using ANOVA (Table 3 and Table 4).

\section{Acrylamide formation}

ACR is generally formed in thermally treated foods $\left(>120^{\circ} \mathrm{C}\right)$, with a high level of carbohydrates [Tareke et al., 2000, 2002; Gökmen, 2015]. As it can be seen in Table 4, the quantities of ACR in the thermally treated plum purée have considerably fluctuated. These differences could depend on plum species, their chemical composition (reducing sugar and amino acid content), and processing conditions (time and temperature) [Becalski et al., 2011]. The model selected revealed the concentration of the ACR formed in the treated purée to highly depend on the selected parameters. A low ACR content was obtained for the eighth running variant $\left(130 \mathrm{~min} / 5.6^{\circ} \mathrm{C}\right.$ ) for both plum species (Table 1). Furthermore, the content of ACR determined in sample P1 was almost 2-fold higher when compared to the sample P2. This significant difference can be due to the higher content of asparagine and reducing sugars. ACR was suggested to be formed by the specific amino acid route due to the suf- 
TABLE 3. ANOVA for the square surface of the acrylamide (ACR) formation during thermal treatment of purée made of Prunus cerasifera (P1) and Prunus domestica (P2) plums.

\begin{tabular}{|c|c|c|c|c|c|}
\hline Statistical parameters & Sum of Squares & df & Mean Square & F Value & $\mathrm{p}$-value \\
\hline \multicolumn{6}{|c|}{ Plum purée P1 } \\
\hline Model & $1.578 \mathrm{E}+006$ & 5 & $3.156 \mathrm{E}+005$ & 101.10 & $<0.0001$ \\
\hline A-Temperature & $9.255 E+005$ & 1 & $9.255 E+005$ & 296.54 & $<0.0001$ \\
\hline B-Time & $1.904 E+005$ & 1 & $1.904 E+005$ & 61.01 & 0.0001 \\
\hline$A B$ & 39823.27 & 1 & 39823.27 & 12.76 & 0.0091 \\
\hline$A^{2}$ & $3.740 E+005$ & 1 & $3.740 E+005$ & 119.83 & $<0.0001$ \\
\hline$B^{2}$ & 88163.21 & 1 & 88163.21 & 28.25 & 0.0011 \\
\hline Residual & 21847.92 & 7 & 3121.13 & & \\
\hline Lack of Fit & 21792.95 & 3 & 7264.32 & 528.60 & $<0.0001$ \\
\hline Pure Error & 54.97 & 4 & 13.74 & & \\
\hline R-Squared & & & 0.9863 & & \\
\hline Adj R-Squared & & & 0.9766 & & \\
\hline \multicolumn{6}{|c|}{ Plum purée P2 } \\
\hline Model & $5.933 E+005$ & 5 & $1.187 E+005$ & 63.15 & $<0.0001$ \\
\hline A-Temperature & $3.388 E+005$ & 1 & $3.388 E+005$ & 180.30 & $<0.0001$ \\
\hline B-Time & 27406.26 & 1 & 27406.26 & 14.58 & 0.0066 \\
\hline$A B$ & 22371.76 & 1 & 22371.76 & 11.91 & 0.0107 \\
\hline$A^{2}$ & $2.046 E+005$ & 1 & $2.046 E+005$ & 108.88 & $<0.0001$ \\
\hline$B^{2}$ & 5039.41 & 1 & 5039.41 & 2.68 & 0.1455 \\
\hline Residual & 13153.71 & 7 & 1879.10 & & \\
\hline Lack of Fit & 13135.39 & 3 & 4378.46 & 955.88 & $<0.0001$ \\
\hline Pure Error & 18.32 & 4 & 4.58 & & \\
\hline R-Squared & & & 0.9783 & & \\
\hline Adj R-Squared & & & 0.9628 & & \\
\hline
\end{tabular}

ficient contents of reducing sugars related to the content of asparagine. The CCD allowed estimating equations which enable predicting the most suitable models for the production of ACR for both samples (P1 and P2) as follows (Eq. 2 and 3 ):

$$
\begin{aligned}
\mathrm{P} 1 \mathrm{ACR}=+ & 24.90+340.14 \mathrm{~A}+154.28 \mathrm{~B}+ \\
& +99.78 \mathrm{AB}+231.87 \mathrm{~A}^{2}+112.58 \mathrm{~B}^{2} \\
\mathrm{P} 2 \mathrm{ACR}=+ & 11.74+205.79 \mathrm{~A}+58.53 \mathrm{~B}+ \\
+ & 74.79 \mathrm{AB}+171.49 \mathrm{~A}^{2}+26.91 \mathrm{~B}^{2}
\end{aligned}
$$

Optimized coding models for ACR contents were represented by regression analysis and variance analysis (ANOVA), and the quadratic models were applied. From the ANOVA (Table 3), it can be seen that both models (P1 and P2) fitted well to optimization data $\left(\mathrm{R}^{2}=0.9863\right.$ and $\mathrm{R}^{2}$ is 0.9783 , respectively), and the $\mathrm{F}$ values (101.10 and 63.15) indicated that the pattern was significant. In this case, the significant model terms were: $\mathrm{A}, \mathrm{B}, \mathrm{AB}, \mathrm{A}^{2}, \mathrm{~B}^{2}$ for $\mathrm{P} 1$ and $\mathrm{A}, \mathrm{B}, \mathrm{AB}, \mathrm{A}^{2}$ for $\mathrm{P} 2$. The ACR content determined in samples $\mathrm{P} 1$ and $\mathrm{P} 2$ was positively correlated with all individual terms, with the greatest influence of the $\mathrm{A}^{2}$ (square of temperature response) for $\mathrm{P} 1$, and $\mathrm{A}$ for $\mathrm{P} 2$ sample.

Figure 1 shows the correlative effect of temperature and time on ACR formation. The content of ACR increased as the processing temperature of the plum purée increased. As it can be seen from the response surface graph (Figure 1A and B), ACR formation was minimal at the shortest time of thermal treatment, between 10 and $20 \mathrm{~min}$. For the plum purée P1, the lowest ACR formation was at the minimum exposure time, between 15 and $20 \mathrm{~min}$. Moreover, an increase in ACR formation at high temperatures $\left(\geq 180^{\circ} \mathrm{C}\right)$ was correlated with an extended thermal treatment interval ( $\geq 25 \mathrm{~min}$ ) (Figure 1A). For the plum purée P2, the combined effect of time and temperature revealed an increased effect on ACR formation at temperatures above $180^{\circ} \mathrm{C}$ and up to $25 \mathrm{~min}$ (Fig- 
TABLE 4. ANOVA for the square surface of the hydroxymethylfurfural (HMF) formation during thermal treatment of purée made of Prunus cerasifera (P1) and Prunus domestica (P2) plums.

\begin{tabular}{|c|c|c|c|c|c|}
\hline Statistical parameters & Sum of Squares & df & Mean Square & F Value & p-value \\
\hline \multicolumn{6}{|c|}{ Plum purée P1 } \\
\hline Model & 23234.07 & 5 & 4646.81 & 39.46 & $<0.0001$ \\
\hline A-Temperature & 18836.10 & 1 & 18836.10 & 159.97 & $<0.0001$ \\
\hline B-Time & 1104.44 & 1 & 1104.44 & 9.38 & 0.0183 \\
\hline$A B$ & 424.31 & 1 & 424.31 & 3.60 & 0.0995 \\
\hline$A^{2}$ & 1851.49 & 1 & 1851.49 & 15.72 & 0.0054 \\
\hline$B^{2}$ & 1386.95 & 1 & 1386.95 & 11.78 & 0.0110 \\
\hline Residual & 824.25 & 7 & 117.75 & & \\
\hline Lack of Fit & 817.24 & 3 & 272.41 & 155.44 & 0.0001 \\
\hline Pure Error & 7.01 & 4 & 1.75 & & \\
\hline R-Squared & & & 0.9657 & & \\
\hline Adj R-Squared & & & 0.9413 & & \\
\hline \multicolumn{6}{|c|}{ Plum purée P2 } \\
\hline Model & 14022.45 & 5 & 2804.49 & 89.37 & $<0.0001$ \\
\hline A-Temperature & 9394.83 & 1 & 9394.83 & 299.38 & $<0.0001$ \\
\hline B-Time & 669.31 & 1 & 669.31 & 21.33 & 0.0024 \\
\hline$A B$ & 280.75 & 1 & 280.75 & 8.95 & 0.0202 \\
\hline$A^{2}$ & 3589.86 & 1 & 3589.86 & 114.40 & $<0.0001$ \\
\hline$B^{2}$ & 292.43 & 1 & 292.43 & 9.32 & 0.0185 \\
\hline Residual & 219.66 & 7 & 31.38 & & \\
\hline Lack of Fit & 217.86 & 3 & 72.62 & 161.41 & 0.0001 \\
\hline Pure Error & 1.80 & 4 & 0.45 & & \\
\hline R-Squared & 0.9846 & & & & \\
\hline Adj R-Squared & 0.9736 & & & & \\
\hline
\end{tabular}

ure 1B). Therefore, time is also an important parameter involved throughout the process, besides the temperature, with a crucial influence in ACR formation. ACR was also formed at the lower temperatures $\left(59.3^{\circ} \mathrm{C}\right.$ and $\left.80^{\circ} \mathrm{C}\right)$, but in lower amount (8.49 and $5.48 \mu \mathrm{g} / \mathrm{kg} \mathrm{DW}$, respectively). In a study conducted by Roach et al. [2003], the formation of ACR in prune juice was highlighted at a temperature range below $120^{\circ} \mathrm{C}\left(98-116^{\circ} \mathrm{C}\right)$ at higher moisture conditions. Additionally, in a study conducted by Amrein et al. [2007], substantial amounts of ACR were found in plums dried at temperatures below $90^{\circ} \mathrm{C}$. Furthermore, besides the temperature and time, the starting reactants present in the food matrices are also important in the Maillard reaction, such as sugar and amino acid type [Yaylayan \& Stadler, 2005]. Although, the ACR formation involves the condensation of the amino group of asparagine (as the principal precursor) and the carbonyl groups of reducing sugars, when the samples are subjected to heat [Becalski et al., 2003; Mottram et al., 2002; Stadler et al., 2002; Zyzak et al., 2003], other amino acids may have a posi- tive effect in obtaining small amounts of ACR in some model systems, such as proline, tryptophan, cysteine, glycine, lysine, etc. [Yu et al., 2013; Koutsidis et al., 2009]. The differences in ACR content between $\mathrm{P} 1$ and $\mathrm{P} 2$ plum purée at a temperature below $80^{\circ} \mathrm{C}$, apart from the variations of heating duration, could also be caused by the higher content of proline in P2 sample, which could lead to a low ACR production. In a study reported by Koutsidis et al. [2009], proline and tryptophan $(80 \%)$ were the most effective amino acids involved in decreasing the ACR levels followed by cysteine and glycine (45-55\%). Thermal treatment (temperature above $120^{\circ} \mathrm{C}$ ) can initiate the deamination and decarboxylation of asparagine, with a higher yield of ACR when a carbonyl source is present [Yaylayan et al., 2003; Weisshaar et al., 2002]. This fact can explain the ACR content in P1 and P2 plums, that are rich in reducing sugars and have a high level of asparagine (Table 2). According to Mottram et al. [2002], the ACR production is slightly influenced by the presence of glutamine and aspartic acid; the ACR quantities obtained were very low, 


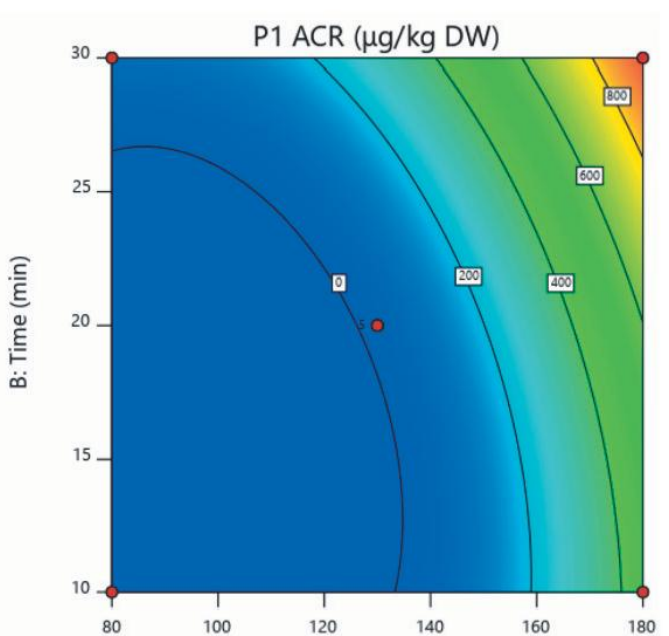

A: Temperature $(C)$

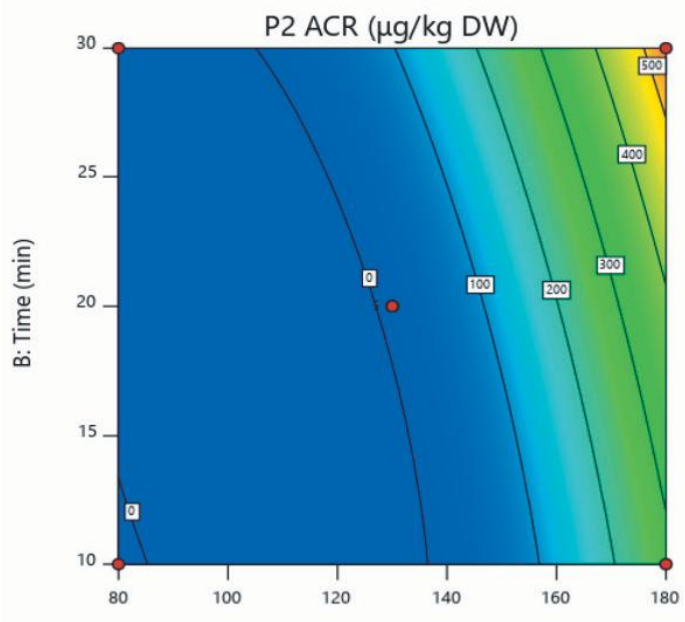

A: Temperature (C)

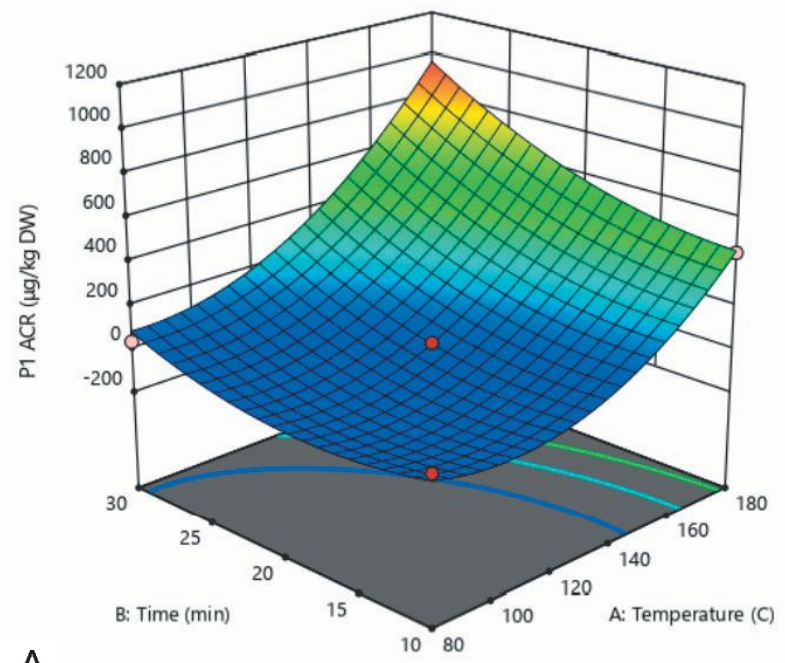

A

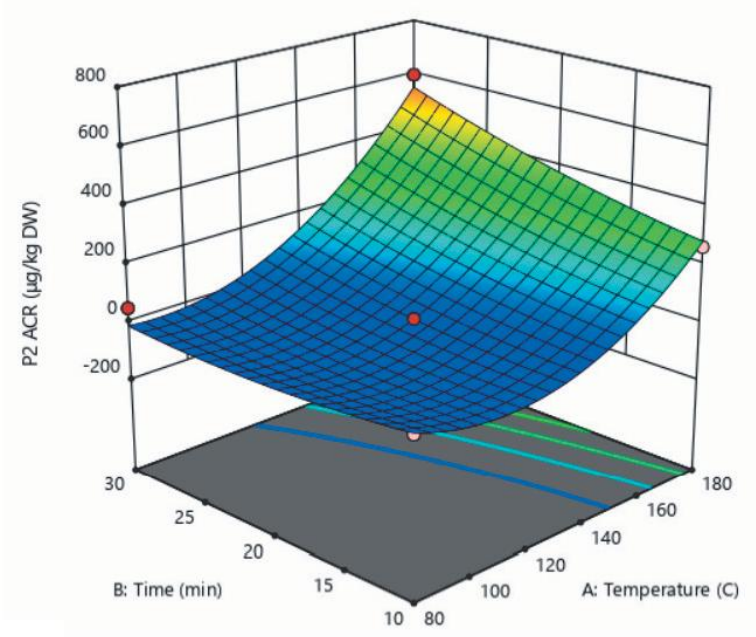

B

FIGURE 1. Contour graphs describing the quantitative correlative effects of time and temperature on the formation of acrylamide (ACR) in puree of plum Prunus cerasifera (P1) (A) and Prunus domestica (P2) (B).

in the range of $0.5-1.0 \mathrm{mg} / \mathrm{mol}$. In another study, Zyzak et al. [2003] used a system model containing: amino acid, glucose, maltodextrin, emulsifier, potato starch, and water, to identify the ACR formation mechanism. The study revealed that a high quantity of ACR was formed $(9270 \mu \mathrm{g} / \mathrm{kg})$ in the model system with asparagine. Additionally, high quantities of ACR were obtained in the system with glutamine $(156 \mu \mathrm{g} / \mathrm{kg})$ and low quantities $(<50 \mu \mathrm{g} / \mathrm{kg})$ in the systems with: alanine, arginine, aspartic acid, cysteine, lysine, methionine, threonine, and valine. In our study, among the amino acids involved in the ACR formation, the highest content was found for asparagine, however limited quantities of alanine, arginine, aspartic acid, lysine, and valine were found as well (Table 2). There is a few data on the ACR levels in thermally obtained plum products such as jams. In a survey on ACR content in various thermally processed plum products from the Slovak market, the level of ACR varied between $15 \mu \mathrm{g} / \mathrm{kg}$ and $46 \mu \mathrm{g} / \mathrm{kg}$ [Kukurová et al., 2015]. In a similar study regarding the ACR levels in foods from the Turkish market, Ölmez et al. [2008] found less than $10 \mu \mathrm{g} / \mathrm{kg}$ ACR in strawberry jam. However, different ACR contents in thermally treated fruits were reported, such as: $14.74-1680 \mu \mathrm{g} / \mathrm{kg}$ in dried plums [Amrein et al., 2007; De Paola et al., 2017], 1432-1502 $\mu \mathrm{g} / \mathrm{kg}$ in dark pears, $0-19 \mu \mathrm{g} / \mathrm{kg}$ in pears, $173.43-879.92 \mathrm{mg} / \mathrm{kg}$ in Abu variety banana fritter, and $30.07-201.18 \mathrm{mg} / \mathrm{kg}$ in Awak variety banana fritter [Daniali et al., 2013].

Regulatory bodies have not established so far the minimum and maximum content of ACR in thermally treated products. Meanwhile, the industrial environment has continuously been concerned to implement measures to reduce the amount of ACR in food based on the application of effective mitigation and quantification strategies. The European Commission recommends the selection of raw material with a reduced level of ACR precursors for the baby jar foods (lowacid and prune-based foods) [Commission Regulation (EU) 2017/2158]. 


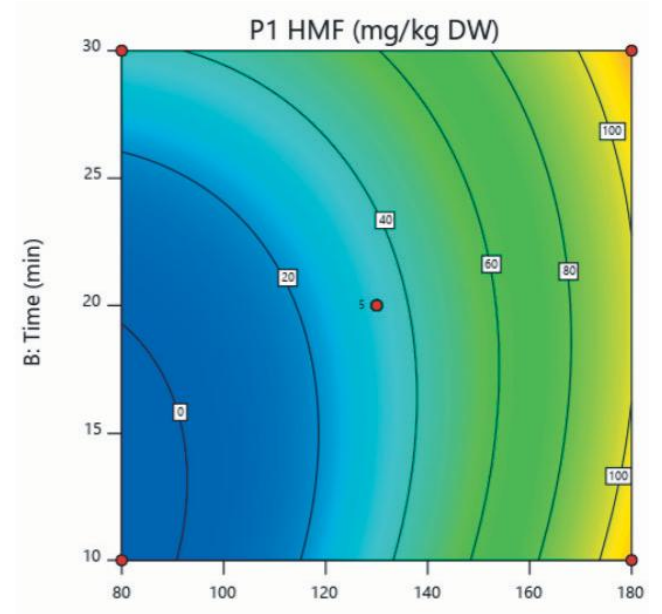

A: Temperature (C)

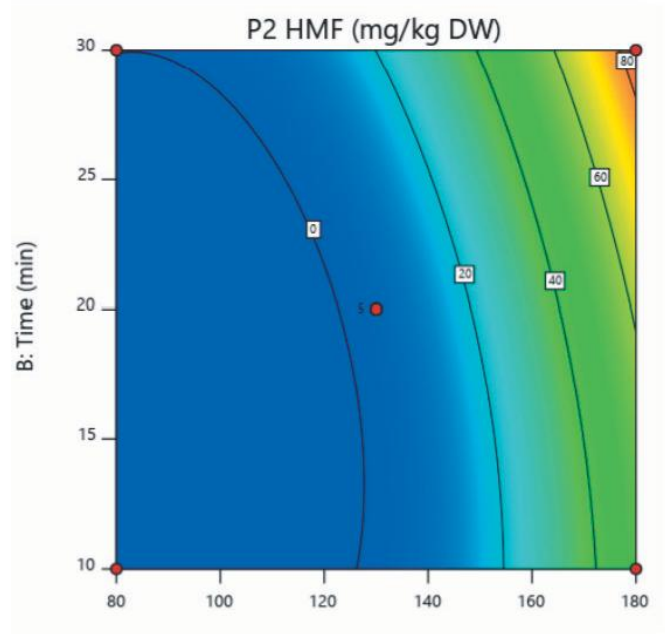

A: Temperature $(C)$
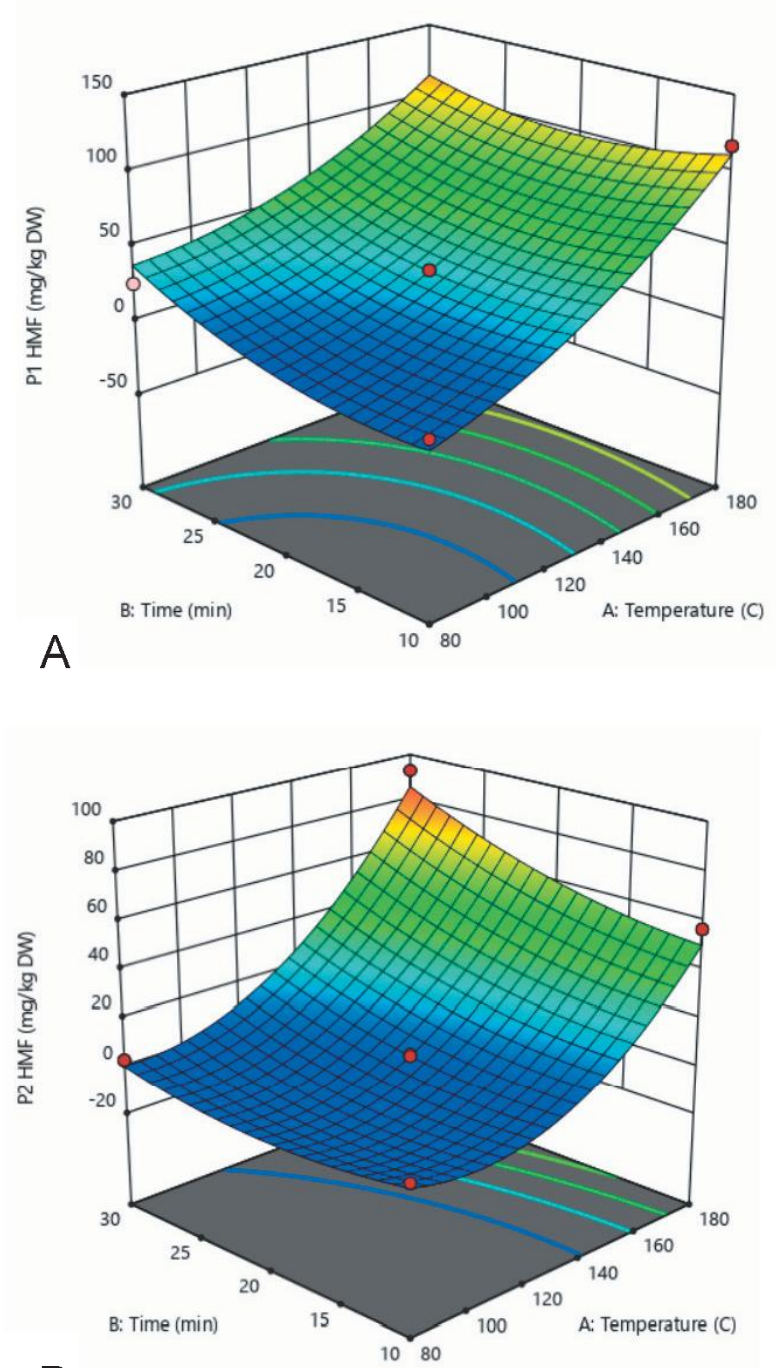

B

FIGURE 2. Contour graphs describing the quantitative correlative effects of time and temperature on the formation of hydroxymethylfurfural (HMF) in puree of plum Prunus cerasifera (P1) (A) and Prunus domestica (P2) (B).

\section{Hydroxymethylfurfural formation}

As it can be seen in Table 1, a low HMF content was found for variants 3 and 4 of P1 sample and for variants 3 , 4 and 8 of $\mathrm{P} 2$ sample. By using low temperatures for heat treatment of plums, the amount of HMF formed was lower, even if the time treatment was longer. The CCD allowed estimating equations which enable predicting the most suitable models for the production of HMF for both samples (P1 and P2) as follows (Eq. 4 and 5):

$$
\begin{aligned}
\mathrm{P} 1 \mathrm{HMF}=+ & 33.71+48.52 \mathrm{~A}+11.75 \mathrm{~B}- \\
& -10.30 \mathrm{AB}+16.31 \mathrm{~A}^{2}+14.12 \mathrm{~B}^{2} \\
\mathrm{P} 2 \mathrm{HMF}=+ & 4.49+34.27 \mathrm{~A}+9.15 \mathrm{~B}+ \\
& +8.38 \mathrm{AB}+22.72 \mathrm{~A}^{2}+6.48 \mathrm{~B}^{2}
\end{aligned}
$$

From the ANOVA (Table 4) for the model chosen, the significant terms are $\mathrm{A}, \mathrm{B}, \mathrm{A}^{2}$, and $\mathrm{B}^{2}$ for plum purée $\mathrm{P} 1$ and $\mathrm{A}, \mathrm{B}, \mathrm{AB}, \mathrm{B}^{2}$ and $\mathrm{A}^{2}$ for plum purée $\mathrm{P} 2$. The HMF content in samples $\mathrm{P} 1$ and $\mathrm{P} 2$ was positively correlated with all individual terms; the A term (temperature response) having the greatest influence on HMF formation. In the case of P1 sample, HMF content was negatively correlated with AB. Figure 2 (A, B) depicts the temperature-time effect on HMF production. HMF formation was minimal at exposure time between 10 and $25 \mathrm{~min}$, and at exposure temperature of around $120^{\circ} \mathrm{C}$. HMF is formed by heating, as an intermediate in the Maillard reaction, [Mauron, 1981; Glatt \& Sommer, 2006]. Kavousi et al. [2015] suggested that the presence of the amino acids, glutamine, glutamic and aspartic acids led to an accelerated formation of HMF compared with the addition of basic amino acids in the model systems. Another mechanism for HMF formation implies direct thermal dehydration of fructose, sucrose, and glucose, without the presence of amino groups [Antal et al., 1990].

By analyzing the 13 running variants, the highest level of $\mathrm{HMF}$ was obtained in the plum purée exposed to $200^{\circ} \mathrm{C}$ for $20 \mathrm{~min}$ for P1 plums $\left(139.06 \mathrm{mg} / \mathrm{kg}\right.$ DW) and to $180^{\circ} \mathrm{C}$ for $30 \mathrm{~min}$ for $\mathrm{P} 2$ plums $(92.88 \mathrm{mg} / \mathrm{kg}$ DW) (Table 1). According 
to Kocadagli et al. [2012], chlorogenic acid promotes the hydrolysis of sucrose to fructose, at a temperature above $180^{\circ} \mathrm{C}$, that may contribute to HMF formation. Moreover, in a study conducted by Zhang et al. [2016] by heating fructose with or without aspartic acid (at $90^{\circ} \mathrm{C} / 48 \mathrm{~h}$ ), to simulate plums drying, it was found that chlorogenic acid increased HMF concentration. In this case, the tested temperature was below $100^{\circ} \mathrm{C}$, but the time of exposure was longer.

The amino acids present in the food matrix may also contribute to the increase of HMF content, probably due to the sucrose hydrolysis which is catalyzed by the presence of amino acids [Lee \& Nagy, 1990]. Moreover, a higher content of HMF was formed by heating fructose with aspartic acid at $\mathrm{pH} 7.0$, compared to fructose alone [Zhang et al., 2016]. In a study conducted by Rada-Mendoza et al. [2002] where HMF was analyzed in various types of fruit jams (apple, apricot, banana, bilberry, fig, lemon, mulberry, orange, pineapple, plum, strawberry), the obtained results varied between 5.5 and $37.7 \mathrm{mg} / \mathrm{kg}$. In our study, the HMF content varied as a function of temperature/time coordinates between 0.25 and $139.06 \mathrm{mg} / \mathrm{kg}$ in $\mathrm{P} 1$, and between 0.18 and $-92.88 \mathrm{mg} / \mathrm{kg}$ in $\mathrm{P} 2$, respectively.

The HMF levels in food are established only for honey by Codex Alimentarius, that allows a maximum concentration of $40 \mathrm{mg} \mathrm{HMF} / \mathrm{kg}$ of productand also by the industry that set an upper limit for fruit juice at $20 \mathrm{mg} / \mathrm{kg}$ [Morales et al., 2008]. For plum products and jams, the regulatory bodies have not set a limit for HMF content.

\section{Global optimization}

The "Desirability" approach is one of the most widely used methods in the industry for optimizing multiple response processes. The global desirability function is defined as the geometric mean of the partial functions. A non-zero value of desirability implies that all the selected criteria were in a good combination and a value closest to 1 shows the best of combinations. Therefore, for sample P1 a 0.895 value of Desirability was obtained, that implied value of $27.8 \mathrm{mg} / \mathrm{kg}$ DW for HMF and a value of $3.90 \mu \mathrm{g} / \mathrm{kg}$ DW for ACR. For sample P2, similar results were obtained, such as a 0.979 value of Desirability which correlates to a minimum of $3.95 \mathrm{mg} / \mathrm{kg}$ DW for HMF and $8.74 \mu \mathrm{g} / \mathrm{kg}$ DW for ACR.

\section{CONCLUSIONS}

Our study data suggest that ACR is formed in the heat-treated plum purée samples through the specific amino acid pathway and is due to the high contents of reducing sugars and asparagine. In general, the contents of ACR and HMF in the tested plum purées highly depended on the applied combination of time and temperature, with a minimum ACR content obtained between 10 and 20 min and an increase in contents of both tested toxicants at higher temperature.

Central Composite Design model was used to estimate equations predicting the most suitable models for the production of ACR and HMF in the treated samples. The global desirability of the both selected varieties were close to 1 , showing the best of combinations. Therefore, the optimal pa- rameters in terms of temperatures and time combination that should be applied are: $114.2^{\circ} \mathrm{C} / 23.8$ min for Prunus cerasifera, and $127.7^{\circ} \mathrm{C} / 21 \mathrm{~min}$ for Prunus domestica.

\section{RESEARCH FUNDING}

This work was supported by a grant of the Ministry of National Education, CNCS - UEFISCDI, project number PN-II-ID-PCE-2012-4-0509. The infrastructure used for experiments was financially supported by the European Regional Development Fund through the implementation of the projects No ITMS 26240220091 and 26240120042.

\section{CONFLICT OF INTERESTS}

Authors declare no conflict of interests.

\section{REFERENCES}

1. Abraham, K., Gürtler, R., Berg, K., Heinemeyer, G., Lampen, A., Appel, K.E. (2011). Toxicology and risk assessment of 5-hydroxymethylfurfural in food. Molecular Nutrition \& Food Research, 55(5), 667-678.

2. Amrein, T.M., Andres, L., Escher, F., Amadò, R. (2007). Occurrence of acrylamide in selected foods and mitigation options. Food Additives \& Contaminants, 24(suppl.), 13-25.

3. Antal, M.J., Mok, W.S., Richards, G.N. (1990). Kinetic studies of the reactions of ketoses and aldoses in water at high-temperature. 1. Mechanism of formation of 5-(hydroxymethyl)-2-furaldehyde from D-fructose and sucrose. Carbohydrate Research, 199(1), 91-109.

4. AOAC: Official Methods of Analysis of the AOAC International (1995). 16 $6^{\text {th }}$ ed. Method 970.12. Association of Official Analytical Chemists International. Washington, DC, USA.

5. Becalski, A., Brady, B., Feng, S., Gauthier, B.R., Zhao, T. (2011). Formation of acrylamide at temperatures lower than $100^{\circ} \mathrm{C}$ : the case of prunes and a model study. Food Additives \& Contaminants: Part A, 28(6), 726-730.

6. Becalski, A., Lau, B.P.Y., Lewis, D., Seaman, S.W. (2003). Acrylamide in foods: Occurrence, sources, and modeling. Journal of Agricultural and Food Chemistry, 51 (3), 802-808.

7. Birwal, P., Deshmukh, G., Saurabh, S.P., Pragati, S. (2017). Plums: a brief introduction. Journal of Food Nutrition and Population Health, 1, 1-5.

8. Blank, I., Robert, F., Goldmann, T., Pollien, P., Varga, N., Devaud, S., Saucy, F., Huynh-Ba, T., Stadler, R.H. (2005). Mechanisms of acrylamide formation Maillard-induced transformation of asparagine. In M. Friedman, D. Mottram (eds.), Chemistry and Safety of Acrylamide in Food, Springer Science + Business Media, Inc., New York, USA, pp. 171-189.

9. Capuano, E., Fogliano, V. (2011). Acrylamide and 5-hydroxymethylfurfural (HMF): A review on metabolism, toxicity, occurrence in food and mitigation strategies. LWT - Food Science and Technology, 44(4), 793-810.

10. Ciesarová, Z., Kukurová, K., Bednáriková, A., Morales, F.J. (2009). Effect of heat treatment and dough formulation on the formation of Maillard reaction products in fine bakery products-benefits and weak points. Journal of Food and Nutrition Research, 48(1), 20-30. 
11. Claus, A., Weisz, G.M., Schieber, A., Carle, R. (2006). Pyrolytic acrylamide formation from purified wheat gluten and gluten-supplemented wheat bread rolls. Molecular Nutrition \& Food Research, 50(1) 87-93.

12. Commission Regulation (EU) 2017/2158 of 20 November 2017 establishing mitigation measures and benchmark levels for the reduction of the presence of acrylamide in food (Text with EEA relevance) Official Journal of the European Union L 304/24. [https://eur-lex.europa.eu/legal-content/EN/TXT/HTML/?uri= CELEX:32017R2158\&from=EN]. (accessed 01.05.2018).

13. Constantin, O.E., Kukurová, K., Neagu, C., Bednáriková, A., Ciesarová, Z., Râpeanu, G. (2014). Modelling of acrylamide formation in thermally treated red bell peppers (Capsicum annuum L.). European Food Research and Technology, 238(1), 149-156.

14. Daniali, G., Jinap, S., Hanifah, N.L., Hajeb, P. (2013). The effect of maturity stages of banana on the formation of acrylamide in banana fritters. Food Control, 32 (2), 386-391.

15. De Paola, E.L., Montevecchi, G., Masino, F., Garbini, D., Barbanera, M., Antonelli, A. (2017). Determination of acrylamide in dried fruits and edible seeds using QuEChERS extraction and LC separation with MS detection. Food Chemistry, 217, 191-195.

16. Friedman, M. (1996). Food browning and its prevention: an overview. Journal of Agricultural and Food Chemistry, 44(3), 631-653.

17. Glatt, H.R., Sommer, Y. (2006). Health risks by 5-hydroxymethylfurfural (HMF) and related compounds. In K. Skog, J. Alexander (eds.), Acrylamide and Other Hazardous Compounds in Heat-Treated Foods, Woodhead Publishing, Cambridge, UK, pp. 328-357.

18. Gökmen, V. (2015). Introduction: potential safety risks associated with thermal processing of foods. In V. Gökmen (ed.), Acrylamide in Food: Analysis, Content and Potential Health Effects, Academic Press, Amsterdam, Netherlands, pp. xxi- xxvi.

19. Gökmen, V., Açar, Ö.C., Serpen, A., Morales, F.J. (2008). Effect of leavening agents and sugars on the formation of hydroxymethylfurfural in cookies during baking. European Food Research and Technology, 226(5), 1031-1037.

20. Granvogl, M., Schieberle, P. (2006). Thermally generated 3-aminopropionamide as a transient intermediate in the formation of acrylamide. Journal of Agricultural and Food Chemistry, 54(16), 5933-5938.

21. Kavousi, P., Mirhosseini, H., Ghazali, H., Ariffin, A.A. (2015). Formation and reduction of 5-hydroxymethylfurfural at frying temperature in model system as a function of amino acid and sugar composition. Food Chemistry, 182, 164-170.

22. Kocadağlı, T., Göncüoğlu, N., Hamzalığlu, A., Gökmen, V. (2012). In depth study of acrylamide formation in coffee during roasting: role of sucrose decomposition and lipid oxidation. Food \& Function, 3(9), 970-975.

23. Koutsidis, G., Simons, S.P., Thong, Y.H., Haldoupis, Y., Mojica-Lazaro, J., Wedzicha, B.L., Mottram, D.S. (2009). Investigations on the effect of amino acids on acrylamide, pyrazines, and Michael addition products in model systems. Journal of Agricultural and Food Chemistry, 57(19), 9011-9015.

24. Kukurová, K., Constantin, O.E., Dubová, Z., Tobolková, B., Suhaj, M., Nystazou, Z., Rapeanu, G., Ciesarová, Z. (2015). Acrylamide content and antioxidant capacity in thermally processed fruit products. Potravinarstvo, 9(1), 90-94.
25. Lee, H.S., Nagy, S. (1990). Relative reactivities of sugars in the formation of 5-hydroxymethylfurfural in sugar-catalyst model systems. Journal of Food Processing and Preservation, 14(3), 171-178.

26. Leong, S.Y., Oey, I. (2012). Effects of processing on anthocyanins, carotenoids and vitamin $\mathrm{C}$ in summer fruits and vegetables. Food Chemistry, 133(4), 1577-1587.

27. Mauron, J. (1981). The Maillard reaction in food; a critical review from the nutritional standpoint. Progress in Food and Nutrition Science, 5(1-6), 5-35.

28. Morales, F.J. (2008). Process-induced food toxicants: Occurrence, formation, mitigation, and health risks. 2008, In Hydroxymethylfurfural (HMF) and Related Compounds. John Wiley \& Sons, Inc., pp. 135-174.

29. Mottram, D.S., Wedzicha B.L., Dodson A.T. (2002). Acrylamide is formed in the Maillard reaction. Nature, 419(6906), 448-449.

30. Nguyen, H.T., Peters, R.J., Van Boekel, M.A. (2016). Acrylamide and 5-hydroxymethylfurfural formation during baking of biscuits: Part I: Effects of sugar type. Food Chemistry, 192, 575-585.

31. Nursten, H. (2005). The Maillard Reaction: Chemistry, Biochemistry and Implications, The Royal Society of Chemistry: Cambridge, Atheneum Press Ltd, Gateshead, Tyne and Wear, UK., pp. 90-99.

32. Ölmez, H., Tuncay, F., Özcan, N., Demirel, S. (2008). A survey of acrylamide levels in foods from the Turkish market. Journal of Food Composition and Analysis, 21 (7), 564-568.

33. Rada-Mendoza, M., Olano, A., Villamiel, M., Determination of hydroxymethylfurfural in commercial jams and in fruit-based infant foods. Food Chemistry, 2002, 79(4), 513-516.

34. Roach, J.A., Andrzejewski, D., Gay, M.L., Nortrup, D., Musser, S.M. (2003). Rugged LC-MS/MS survey analysis for acrylamide in foods. Journal of Agricultural and Food Chemistry, 51(26), 7547-7554.

35. Sahamishirazi, S., Moehring, J., Claupein, W., Graeff-Hoenninger S. (2017). Quality assessment of 178 cultivars of plum regarding phenolic, anthocyanin and sugar content. Food Chemistry, 214, 694-701.

36. Stadler, R.H., Blank, I., Varga, N., Robert, F., Hau, J., Guy, P., Riediker, S. (2002). Acrylamide from Maillard reaction products. Nature, 419(6906), 449-450.

37. Swedish National Food Administration. (2002). Information about acrylamide in food, [www.slv.seS].

38. Tareke, E., Rydberg, P., Karlsson, P., Eriksson, S., Törnqvist, M. (2000). Acrylamide: A cooking carcinogen?. Chemical Research in Toxicology, 13(6), 517-522.

39. Tareke, E., Rydberg, P., Karlsson, P., Eriksson, S., Tornqvist, M. (2002). Analysis of acrylamide, a carcinogen formed in heated foodstuffs. Journal of Agricultural and Food Chemistry, 50(17), 4998-5006.

40. Weisshaar, R., Gutsche, B. (2002). Formation of acrylamide in heated potato products-model experiments pointing to asparagine as precursor. Dtsch Lebensmitt Rundsch, 98(11), 397-400.

41. Yasuhara, A., Tanaka, Y., Hengel, M., Shibamoto, T. (2003). Gas chromatographic investigation of acrylamide formation in browning model systems. Journal of Agricultural and Food Chemistry, 51, 3999-4003.

42. Yaylayan, V.A., Stadler, R.H. (2005). Acrylamide formation in food: a mechanistic perspective. Journal of AOAC International, 88(1), 262-267. 
43. Yaylayan, V.A., Wnorowski, A., Locas, C.P. (2003). Why asparagine needs carbohydrates to generate acrylamide. Journal of Agricultural and Food Chemistry, 51 (6), 1753-1757.

44. Yu, M., Ou, S., Liumengzi, D., Huang, C., Zhang, G. (2013). Effect of ten amino acids on elimination of acrylamide in a model reaction system. African Journal of Food Science, 7(9), 329-333.

45. Zhang, Z., Zou, Y., Wu, T., Huang, C., Pei, K., Zhang, G., Ou, S. (2016). Chlorogenic acid increased 5-hydroxymethylfurfural formation when heating fructose alone or with aspartic acid at two pH levels. Food Chemistry, 190, 832-835.

46. Zyzak, D.V., Sanders, R.A., Stojanovic, M., Tallmadge, D.H., Eberhart, B.L., Ewald, D.K., Villagran, M.D. (2003). Acrylamide formation mechanism in heated foods. Journal of Agricultural and Food Chemistry, 51(16), 4782-4787.

Submitted: 21 September 2018. Revised: 1 February and 15 March 2019. Accepted: 2 April 2019. Published on-line: 31 May 2019. 